\title{
Optimal anticoagulation in elderly patients with atrial fibrillation: Which drug at which dose?
}

\author{
Jo-Nan Liao ${ }^{1,2 *}$, Yi-Hsin Chan ${ }^{3-5 *}$, Ling Kuo ${ }^{1,2}$, Chuan-Tsai Tsai ${ }^{1,2}$, Su-Shen Lim ${ }^{1,2}$, Tze-Fan Chao ${ }^{1,2}$ \\ 'Division of Cardiology, Department of Medicine, Taipei Veterans General Hospital, Taipei, Taiwan \\ ${ }^{2}$ Institute of Clinical Medicine and Cardiovascular Research Center, National Yang Ming Chiao Tung University, Taipei, Taiwan \\ ${ }^{3}$ Cardiovascular Department, Chang Gung Memorial Hospital, Linkou, Taoyuan, Taiwan \\ ${ }^{4}$ College of Medicine, Chang Gung University, Taoyuan, Taiwan \\ ${ }^{5}$ Microscopy Core Laboratory, Chang Gung Memorial Hospital, Linkou, Taoyuan, Taiwan \\ *Both authors equally contributed to the study
}

Correspondence to:

Tze-Fan Chao, MD, PhD,

Division of Cardiology,

Department of Medicine,

Taipei Veterans General Hospital,

No. 201, Sec. 2, Shih-Pai Road,

Taipei, Taiwan,

phone: 886228757156

e-mail: eyckeyck@gmail.com

Copyright by the Author(s), 2022

DOI: 10.33963/KP.a2022.0046

Received:

February 11, 2022

Accepted:

February 14, 2022

Early publication date:

February 14, 2022

\begin{abstract}
A B S TR A C T
Aging is an important risk factor for adverse events in elderly patients with atrial fibrillation (AF) and complicates the management of anticoagulation. Underuse of oral anticoagulants (OACs) is common in elderly patients because of comorbidities, the altered physiological function of multiple organs, frailty, risk of falls, and the lack of randomized controlled trials (RCTs) specifically for elderly patients. Nevertheless, current data still support OACs use for reducing ischemic stroke with positive net clinical benefits. Sub-analyses of RCTs and real-world cohort studies showed that non-vitamin $\mathrm{K}$ antagonist OACs (NOACs) would be more favorable choices compared to warfarin for stroke prevention in the elderly. This review will discuss important data on stroke prevention and the use of NOACs in elderly AF patients.

Key words: anticoagulation, atrial fibrillation, elderly, NOAC, stroke
\end{abstract}

\section{INTRODUCTION}

Atrial fibrillation (AF) is the most common sustained arrhythmia worldwide and the prevalence has been increasing with the aging of the population worldwide [1, 2]. AF increases the risks of ischemic stroke and systemic embolism (IS/SE), and the $\mathrm{CHA}_{2} \mathrm{DS}_{2}$-VASc score is recommended to guide the use of oral anticoagulant (OAC) for stroke prevention [3-6]. Age itself is one of the components of the $\mathrm{CHA}_{2} \mathrm{DS}_{2}$-VASc score, with 1 score assigned for age 65-74 years and 2 scores for age $\geq 75$ years. The analysis of the Atrial Fibrillation Investigators database observed a $45 \%$ increase of risk of ischemic stroke per decade in age (hazard ratio [HR], 1.45; 95\% confidence interval [Cl], 1.26-1.66) [7]. Even in patients aged $\geq 65$ years, a gradual increase of ischemic stroke with an increase of aging is still evident (Figure 1) [10-13]. Aging also increases the risk of intracranial hemorrhage $(\mathrm{ICH})$ and major bleeding and contributes to the HAS-BLED score $[8,9]$ together with other risk factors (Figure 1) [10-13]. Besides, aging alters the physiological functions of multiple organs and might affect medication concentrations and exposure [14]. Therefore, OAC use in elderly AF patients, especially those aged $\geq 75$ years, is a complex issue involving the balance between efficacy and safety.

\section{"Old age" should not be the only reason to withhold oral anticoagulants for AF patients}

In real-world practice, underuse of $O A C$ is common in elderly AF patients because of the fear of bleeding and the lack of specific guidelines. However, a nationwide cohort study by Chao et al. demonstrated a decreased risk of stroke (HR, 0.69; 95\% Cl, 0.49-0.96) and a similar risk of ICH with warfarin compared to no antithrombotic treatment in AF patients aged $\geq 90$ years. Warfarin was still associated with a positive net clinical benefit compared 


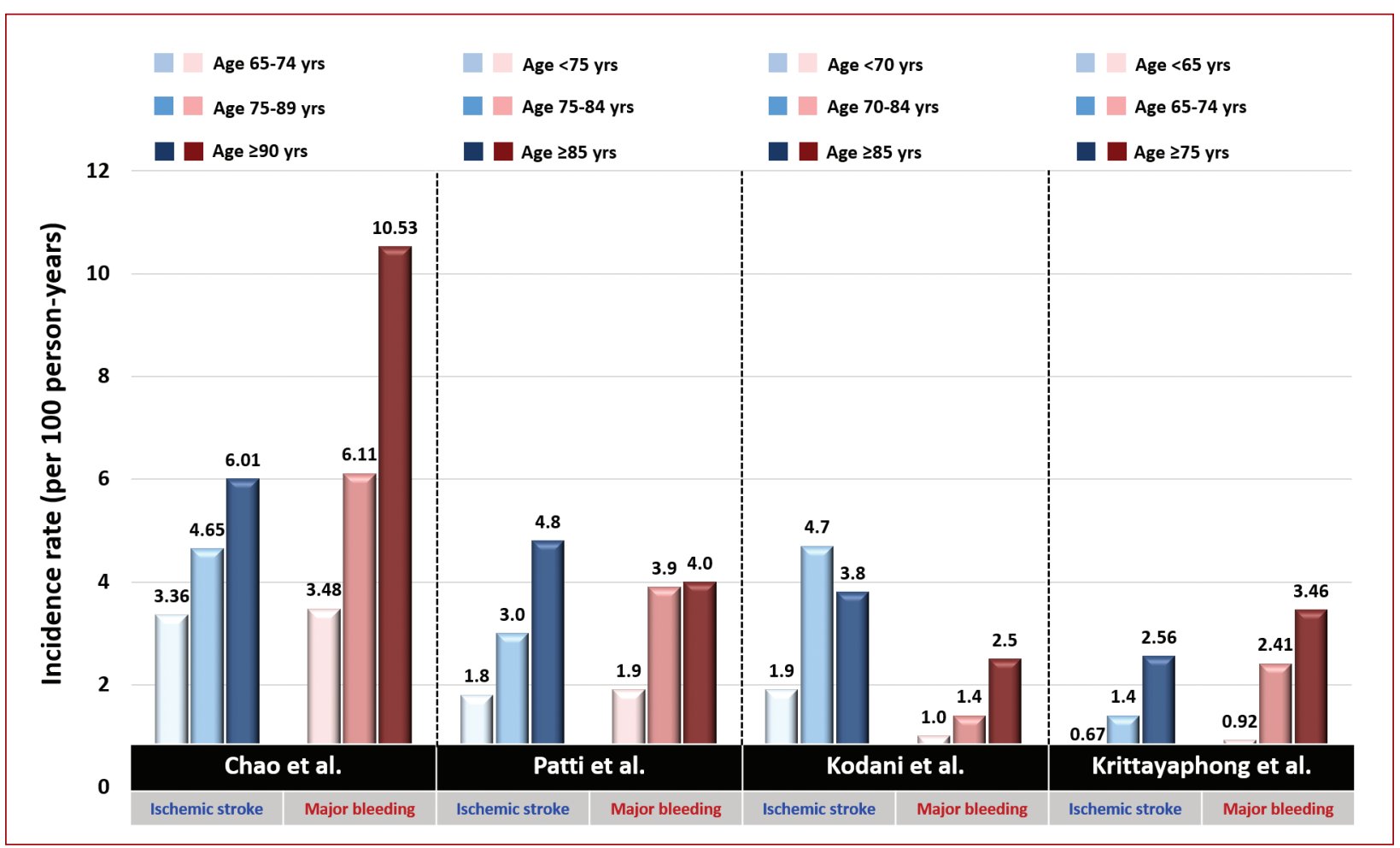

Figure 1. Risks of ischemic stroke and major bleeding in elderly patients with AF. Elderly patients are at increased risks of ischemic stroke and major bleeding, and the risks continues to rise at even advanced age. Data used in the figure were adapted from the papers by Chao et al., Patti et al., Kodani et al., and Krittayaphong et al. [10-13]

Abbreviations: $\mathrm{AF}$, atrial fibrillation

to antiplatelet treatment [15]. The sub-analysis from the prospective PREFER in AF study (PREvention oF Thromboembolic Events-European Registry in Atrial Fibrillation) reported the presence of a significant gradient of net clinical benefit according to age strata with warfarin use, with the oldest patients deriving the greatest advantage [11]. Even among the very elderly ( $>90$ years) AF patients perceived to be at high risk for bleeding, for example, those with a history of $\mathrm{ICH}$, gastrointestinal (GI) bleeding, or chronic kidney disease, non-vitamin $\mathrm{K}$ antagonist OACs (NOACs) were associated with a lower composite risk of ischemic stroke, ICH, major bleeding, or mortality (HR, 0.763; 95\% $\mathrm{Cl}, 0.702-0.830)$ compared to non-OACs [16]. Therefore, old age should not be the only reason not to prescribe $\mathrm{OAC}$ in patients with AF.

\section{NOACs would be more favorable choices over warfarin in elderly AF patients}

Although NOACs are recommended over warfarin as the preferred choice for stroke prevention in AF in current guidelines [3-6], randomized controlled trials (RCTs) specifically comparing NOACs to warfarin in elderly AF patients are lacking. In landmark trials of NOACs, patients $\geq 75$ years accounted for $30 \%-40 \%$ of all study population [17-20], and patients $\geq 85$ years were even fewer. A meta-analysis including 5 phase-III RCTs reported higher risks of IS/SE and major bleeding in elderly ( $\geq 75$ years) patients compared to non-elderly patients despite the treatment, but the benefi- cial effects of NOACs compared with warfarin in reducing IS/SE and major bleeding remained in the elderly group [21]. Sub-analyses from other landmark trials demonstrated a lower (apixaban and edoxaban) or similar (dabigatran and rivaroxaban) risks of major bleeding with NOACs compared to warfarin for AF patients aged $\geq 75$ years (Figure 2) [22-25]. However, it should be emphasized that the enrollment criteria differ in various NOAC trials, and, therefore, these observations should not be interpreted as an indication that one NOAC is better than others for stroke prevention in the elderly with AF.

Real-world cohort studies might partly make up for the paucity of RCTs regarding NOACs use in elderly AF patients (Table 1) [10, 15, 26-31]. A nationwide cohort study showed that NOACs were associated with a lower risk of ICH and a similar risk of ischemic stroke compared to warfarin in $\mathrm{AF}$ patients aged $\geq 90$ years [15]. Subgroup analysis at different age strata (age $65-74,75-89, \geq 90$ years) in elderly AF patients supported the overall beneficial roles of NOACs compared to warfarin, but there was heterogeneity in treatment effects in different age strata (Figure 3) [10]. Aging seems to be a more dominant factor for ischemic stroke than types of OACs (NOACs or warfarin), but NOACs remained associated with a lower risk of ischemic stroke in patients aged $\geq 90$ years compared to warfarin. In terms of ICH, NOACs behaved better than warfarin irrespective of age strata. Even for patients aged $\geq 90$ years treated with NOACs, their risk of ICH (0.86\%/year) was lower than 


\begin{tabular}{|c|c|c|c|c|c|c|}
\hline & $\begin{array}{l}\text { No. of events } \\
\text { (\%/year) }\end{array}$ & $\begin{array}{c}\text { No. of events } \\
\text { (\%/year) }\end{array}$ & NOACs better & Warfarin better & $\begin{array}{c}\text { Hazard ratio } \\
(95 \% \mathrm{Cl})\end{array}$ & $\mathbf{P}_{i n t}$ \\
\hline ARISTOTLE & Apixaban & Warfarin & & & & \\
\hline Overall & $327(2.13)$ & $462(3.09)$ & $\mapsto-1$ & & $0.69(0.60-0.80)$ & \multirow{4}{*}{0.63} \\
\hline$<65$ yrs & $56(1.2)$ & $72(1.5)$ & $\longmapsto$ & I & $0.78(0.55-1.11)$ & \\
\hline 65 to $<75$ yrs & $120(2.0)$ & $166(2.8)$ & $\mapsto$ & & $0.71(0.56-0.89)$ & \\
\hline$\geq 75$ yrs & $151(3.3)$ & $224(5.2)$ & $\mapsto$ & & $0.64(0.52-0.79)$ & \\
\hline ENGAGE AF-TIMI 48 & Edoxaban (HDER) & Warfarin & & & & \\
\hline Overall & $418(2.75)$ & $524(3.43)$ & - & & $0.80(0.71-0.91)$ & \multirow{4}{*}{0.78} \\
\hline$<65$ yrs & (1.5) & (1.8) & 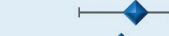 & - & $0.81(0.58-1.12)$ & \\
\hline 65 to $<75$ yrs & (2.5) & (3.3) & $\mapsto$ & & $0.75(0.60-0.94)$ & \\
\hline$\geq 75$ yrs & (4.0) & (4.8) & $\bullet$ & & $0.83(0.70-0.99)$ & \\
\hline RE-LY & Dabigatran $110 \mathrm{mg}$ & Warfarin & & & & \\
\hline Overall & $322(2.71)$ & 397 (3.36) & 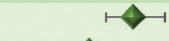 & & $0.80(0.69-0.93)$ & \multirow{4}{*}{0.0003} \\
\hline$<75$ yrs & $138(1.89)$ & $215(3.04)$ & $\vdash \triangleleft$ & & $0.62(0.50-0.77)$ & \\
\hline$\geq 75$ yrs & $204(4.43)$ & $206(4.37)$ & & $\rightarrow$ & $1.01(0.83-1.23)$ & \\
\hline & Dabigatran $150 \mathrm{mg}$ & Warfarin & \multirow{4}{*}{$\mapsto$} & & & \\
\hline Overall & 375 (3.11) & $397(3.36)$ & & & $0.93(0.81-1.07)$ & \multirow{3}{*}{0.0001} \\
\hline$<75$ yrs & $153(2.12)$ & $215(3.04)$ & & & $0.70(0.57-0.86)$ & \\
\hline$\geq 75$ yrs & $246(5.10)$ & $206(4.37)$ & & $\diamond$ & $1.18(0.98-1.42)$ & \\
\hline ROCKET AF & Rivaroxaban $20 \mathrm{mg}$ & Warfarin & & & & \\
\hline Overall & 395 (3.6) & $386(3.4)$ & & & $1.04(0.90-1.20)$ & \multirow{4}{*}{0.59} \\
\hline$<65$ yrs & $59(2.21)$ & $59(2.16)$ & & & $1.02(0.71-1.46)$ & \\
\hline 65 to $<75$ yrs & $113(3.03)$ & $123(3.24)$ & & & $0.94(0.73-1.21)$ & \\
\hline \multirow[t]{2}{*}{$\geq 75$ yrs } & $223(4.86)$ & $204(4.40)$ & & 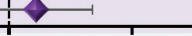 & $1.11(0.92-1.34)$ & \\
\hline & & & 0.5 & 1.5 & & \\
\hline
\end{tabular}

Figure 2. Risks of major bleeding of NOACs compared to warfarin across different age strata in landmark RCTs. Sub-analyses from landmark trials demonstrated a lower (apixaban and edoxaban) or similar (dabigatran and rivaroxaban) risks of major bleeding with NOACs compared to warfarin for AF patients aged $\geq 75$ years. Data used in the figure were adapted from the papers by Kato et al., Eikelboom et al., Halvorsen et al., and Goodman et al. [22-25].

Abbreviations: $\mathrm{Cl}$, confidence interval; HDER, higher-dose edoxaban regimen; NOACs, non-vitamin $\mathrm{K}$ antagonist oral anticoagulants; $\mathrm{P}_{\text {int' }}, \mathrm{P}$ for interaction; RCTs, randomized controlled trials

Table 1. Real-world cohort studies in elderly patients with atrial fibrillation: NOACs compared to warfarin

\begin{tabular}{|c|c|c|c|c|c|c|c|c|}
\hline Studies & Year & Country & $\begin{array}{l}\text { Definition } \\
\text { of elderly }\end{array}$ & NOACs & Warfarin & $\begin{array}{c}\text { IS or IS/SE } \\
\text { HR }(95 \% \mathrm{CI})\end{array}$ & $\begin{array}{l}\text { Major bleeding } \\
\text { HR }(95 \% \mathrm{CI}\end{array}$ & $\begin{array}{c}\text { ICH } \\
(\mathrm{HR}, 95 \% \mathrm{Cl})\end{array}$ \\
\hline \multirow[t]{2}{*}{ Lai et al. [26] } & 2018 & Taiwan & $\geq 85$ years & Dabigatran $(n=1180)$ & $\mathrm{n}=1180$ & $1.25(0.75-2.09)$ & $\begin{array}{l}\text { (Gl bleeding) } \\
1.21(0.76-1.91)\end{array}$ & $0.31(0.10-0.97)$ \\
\hline & & & & Rivaroxaban $(n=1207)$ & $\mathrm{n}=1207$ & $1.02(0.64-1.65)$ & $\begin{array}{l}\text { (Gl bleeding) } \\
0.81(0.47-1.38)\end{array}$ & $0.47(0.17-1.26)$ \\
\hline \multirow[t]{3}{*}{ Tsai et al. [27] } & 2020 & Taiwan & $\geq 85$ years & Dabigatran $(n=3893)$ & $\mathrm{n}=3893$ & $0.932(0.811-1.114)$ & $0.906(0.769-1.031)$ & $0.496(0.357-0.688)$ \\
\hline & & & & Rivaroxaban $(\mathrm{n}=3913)$ & $\mathrm{n}=3913$ & $0.781(0.649-0.941)$ & $0.868(0.753-1.001)$ & $0.453(0.309-0.663)$ \\
\hline & & & & Apixaban $(n=574)$ & $n=574$ & $0.540(0.277-1.054)$ & $0.874(0.526-1.456)$ & $0.182(0.022-1.475)$ \\
\hline Chao et al. [15] & 2018 & Taiwan & $\geq 90$ years & $\begin{array}{l}\text { NOACs ( } 37 \% \text { Dabigatran; } \\
57 \% \text { Rivaroxaban; } \\
6 \% \text { Apixaban) } \\
(n=978)\end{array}$ & $n=768$ & $1.16(0.61-2.22)$ & $0.95(0.63-1.44)$ & $0.32(0.10-0.97)$ \\
\hline Chao et al. [10] & 2020 & Taiwan & $\begin{array}{l}75-89 \\
\text { years }\end{array}$ & $\begin{array}{l}\text { NOACs ( } 50 \% \text { Dabigatran; } \\
5 \% \text { Apixaban; } \\
45 \% \text { Rivaroxaban) } \\
\text { ( } \mathrm{n}=28179)\end{array}$ & $n=10609$ & $0.825(0.758-0.897)$ & $0.857(0.796-0.923)$ & $0.564(0.474-0.670)$ \\
\hline \multirow[t]{4}{*}{ Chan et al. [28] } & 2019 & Taiwan & $\geq 75$ years & Edoxaban & & $0.65(0.44-0.96)$ & $0.47(0.29-0.76)$ & $0.40(0.18-0.88)$ \\
\hline & & & & Apixaban & & $0.56(0.39-0.79)$ & $0.30(0.19-0.49)$ & $0.35(0.17-0.69)$ \\
\hline & & & & Rivaroxaban & & $0.70(0.51-0.97)$ & $0.56(0.39-0.82)$ & $0.44(0.24-0.81)$ \\
\hline & & & & Dabigatran & & $0.71(0.51-0.98)$ & $0.68(0.47-0.97)$ & $0.52(0.29-0.94)$ \\
\hline Hanon et al. [29] & 2021 & France & $\geq 80$ years & Rivaroxaban $(n=995)$ & $\mathrm{n}=908$ & $0.44(0.15-1.30)$ & $0.53(0.33-0.85)$ & $0.26(0.09-0.80)$ \\
\hline \multirow{3}{*}{$\begin{array}{l}\text { Deitelzweig et } \\
\text { al. [30] }\end{array}$} & 2019 & US & $\geq 80$ years & Apixaban $(n=18897)$ & $\mathrm{n}=18897$ & $0.57(.47-0.70)$ & $0.53(0.48-0.58)$ & $0.44(0.34-0.57)$ \\
\hline & & & & Dabigatran $(n=6698)$ & $n=6698$ & $0.87(0.65-1.16)$ & $0.90(0.77-1.05)$ & $0.50(0.33-0.77)$ \\
\hline & & & & Rivaroxaban $(n=25917)$ & $\mathrm{n}=25917$ & $0.73(0.63-0.85)$ & $0.81(0.67-0.99)$ & $0.77(0.63-0.94)$ \\
\hline Russo et al. [31] & 2020 & Italy & $\geq 80$ years & NOACs $(n=252)$ & $\mathrm{n}=504$ & $1.00(0.46-2.19)$ & $0.82(0.50-1.34)$ & $0.29(0.07-1.25)$ \\
\hline
\end{tabular}

Abbreviations: AF, atrial fibrillation; Gl, gastrointestinal; ICH, intracranial hemorrhage; IS/SE, ischemic stroke/system embolism; NOACs, non-vitamin $\mathrm{K}$ antagonist oral anticoagulants 


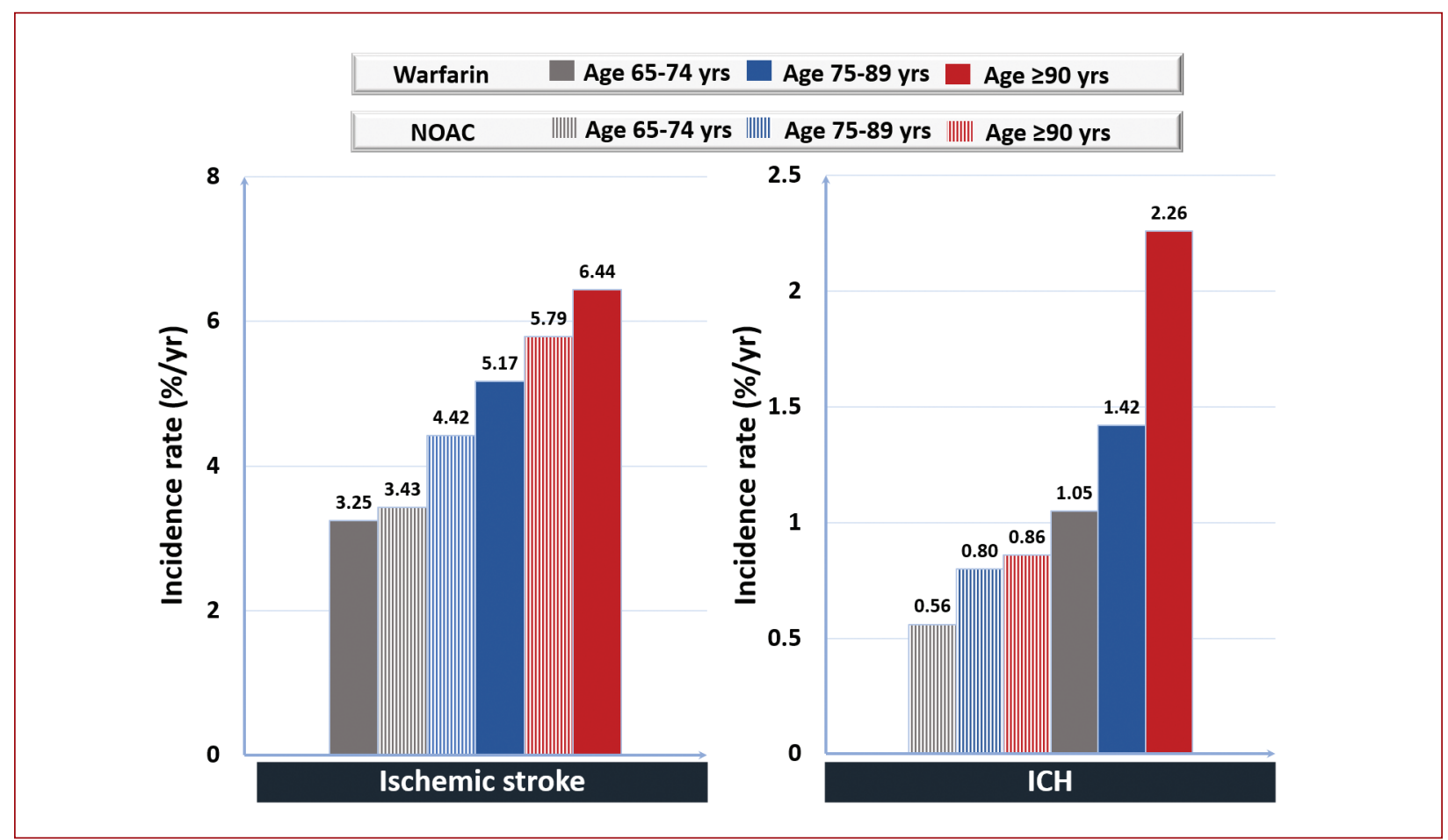

Figure 3. Annual risks of ischemic stroke and ICH in patients treated with NOACs or warfarin in different age strata. Aging seems to be a more dominant factor of ischemic stroke than types of OACs (NOACs or warfarin), but NOACs remained associated with a lower risk of ischemic stroke in patients aged $\geq 90$ years compared to warfarin. In terms of ICH, NOACs behaved better than warfarin irrespective of age strata. Even for patients aged $\geq 90$ years treated with NOACs, their risk of ICH (0.86\%/year) was lower than in "younger" patients, aged $65-74$ years, receiving warfarin (1.05\%/year). Data used in the figure were adapted from the papers by Chao et al. [10]

Abbreviations: ICH, intracranial hemorrhage; OAC - oral anticoagulants; other — see Figure 2

"younger" patients aged 65-74 years receiving warfarin (1.05\%/year) (Figure 3) [10]. The patterns of the associations between the risk of $\mathrm{ICH}$ and age seem to be different for warfarin and NOACs (Figure 4) [10]. For warfarin, the risk of $\mathrm{ICH}$ increased in parallel to the increase in age, while the curve of $\mathrm{ICH}$ risk seemed to be relatively flat with NOACs when age increased. Therefore, the absolute risk reduction in $\mathrm{ICH}$ with NOACs, compared with warfarin, would be more evident in the elderly AF population. Results from the meta-analysis of 11 RCTs and observational studies also favored NOAC use over VKAs in patients aged $>75$ years based on improved overall outcomes [32].

In daily practice, the introduction of NOACs did change the landscape of stroke prevention in the elderly AF population. In a recent nationwide report from Taiwan, the introduction of NOACs increased the initiation rates of OACs in elderly AF patients, which were related to the lower risk of ischemic stroke and mortality over time (Figure 5) [33].

\section{DOSING OF NOACS IN THE ELDERLY}

There are different dose reduction criteria for each NOAC. Although age had not been a dose reduction criterion in RE-LY (Randomized Evaluation of Long-term Anticoagulation Therapy) [17], dabigatran $150 \mathrm{mg}$ is not recommended for patients aged $\geq 80$ years in Europe, and a lower dose (110 mg) should be considered for patients aged 75-
-79 years. In the ROCKET AF trial (Rivaroxaban Once-Daily, Oral, Direct Factor Xa Inhibition Compared With Vitamin K Antagonism for Prevention of Stroke and Embolism Trial in Atrial Fibrillation) [18], dose reduction is mainly driven by renal function, and age had not been a dose-reduction criterion. Nevertheless, renal function is more often impaired in elderly patients in whom a reduced dose might be justified. Like in the ROCKET AF trial, old age was not a dosage-reduction criterion for edoxaban in the ENGAGE AF-TIMI 48 trial (Effective Anticoagulation with Factor Xa Next Generation in Atrial Fibrillation-Thrombolysis in Myocardial Infarction 48) [20]. In the ARISTOTLE trial (Apixaban for Reduction in Stroke and Other Thromboembolic Events in AF) [19], age directly influenced apixaban dosing as age $\geq 80$ years was one of the three dose-reduction criteria, and the dose of apixaban should be reduced once another dosage reduction criterion was present.

Since renal function is a crucial factor to determine NOAC dosing under most circumstances, accurate evaluation of renal function is important. The most commonly used formulas for estimating renal function include the Cockcroft-Gault (CG) formula, Modified Diet in Renal Disease (MDRD) formula, and Chronic Kidney Disease Epidemiology Collaboration (CKD-EPI) formula. The CG formula is adopted in most RCTs while the MDRD and CKD-EPI formulas are usually applied in real-world practice. Chao 


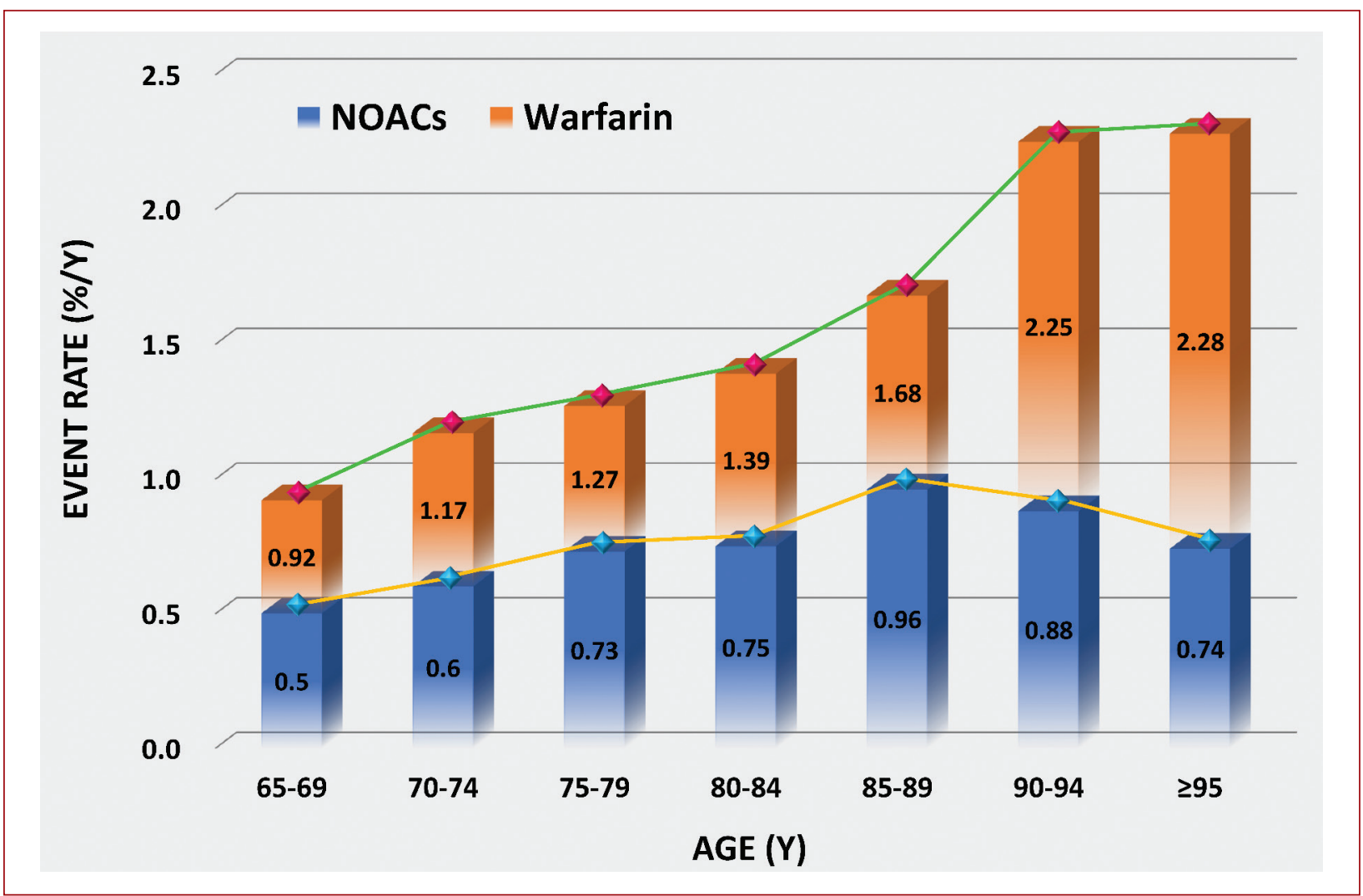

Figure 4. The differences of the risk of $\mathrm{ICH}$ between NOACs and warfarin in different age strata. The patterns of the associations between risk of ICH and age seem to be different for warfarin and NOACs. For warfarin, the risk of ICH increased in parallel to the increase in age, while the curve of ICH risk seemed to be relatively flat with NOACs when age increased. Therefore, the absolute risk reductions in ICH with NOACs, compared with warfarin, would be more evident in the elderly AF population. Data used in the figure were adapted from the papers by Chao et al. [10]

Abbreviations: see Figures 2 and 3

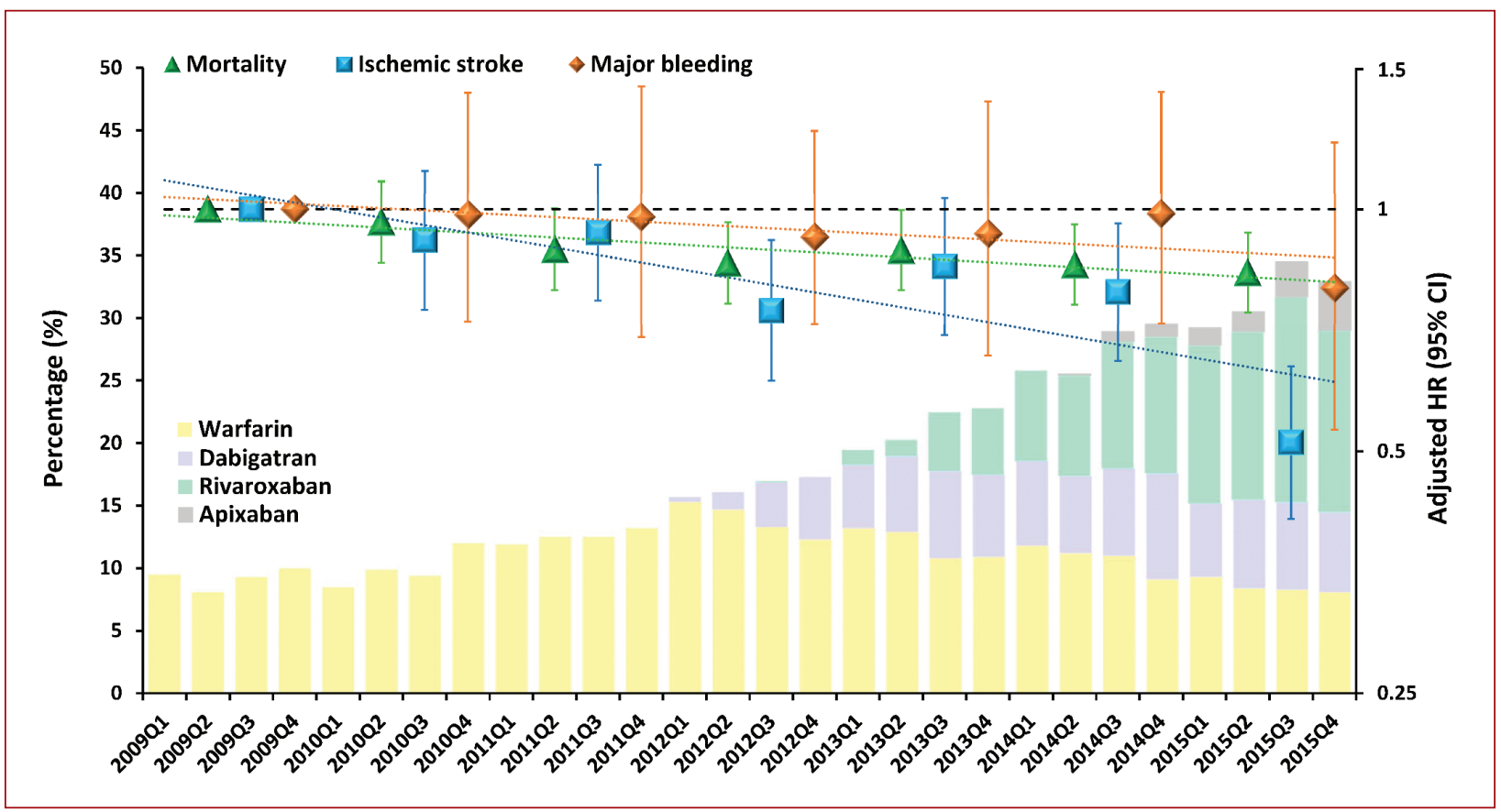

Figure 5. Temporal trends of OACs prescription in elderly AF patients in relation to risks of adverse events. The introduction of NOACs increased the initiation rates of OACs in elderly AF patients which were temporally related to the lower risk of ischemic stroke and mortality over time. The figure was redrawn, and data were adapted from the paper by Cheng et al. [33]

Abbreviations: see Figures 1-3 
et al. [34] found the estimated glomerular filtration rate (eGFR) was overestimated in older patients ( $>75$ years) and low body weights ( $<50 \mathrm{~kg}$ ) using the MDRD and CKD-EPI compared to the CG equation, which might result in inappropriate dosing (mainly overdosing) of NOACs. Importantly, the overdosing may attenuate the benefits of NOACs regarding the risk of major bleeding compared to warfarin [35]. Therefore, the CG equation should be the preferred equation to calculate eGFR and determine the dosing of NOACs. This issue is particularly important for elderly AF patients.

\section{WHAT IS THE OPTIMAL CHOICE AND DOSE OF NOACS IN ELDERLY AF PATIENTS?}

Head-to-head comparisons among different NOACs in elderly patients with AF are still lacking, and only some indirect comparisons are available. A meta-analysis including 5 phase-III RCTs (ARISTOTLE, ENGAGE AF-TIMI48, Japanese-ROCKET AF [J-ROCKET AF], RE-LY, ROCKET AF) showed that standard-dose NOAC exhibited superior efficacy in the elderly ( $\geq 75$ years) group, whereas low-dose NOACs showed equivalent efficacy compared to warfarin [21]. The efficacy of NOACs was consistent after excluding results from the edoxaban $30 \mathrm{mg}$-based regimen and the J-ROCKET AF trial. With regard to safety issues, although the overall major bleeding rate was significantly lower in the NOAC group than in the warfarin group, the benefit is observed mainly in non-elderly patients in whom both standard-dose and low-dose regimens of NOACs exhibited superior safety. In the elderly group, NOACs and warfarin exhibited equivalent safety, regardless of the NOAC dosage. The risk of ICH was significantly lower in the NOAC group than in the warfarin group, regardless of age or NOAC dosage. Moreover, the risk of GI bleeding was significantly higher in the standard-dose NOACs group than in the warfarin group in both elderly and non-elderly groups; low-dose NOACs showed a similar risk of Gl bleeding in the elderly group and a lower risk in the non-elderly group. NOACs exhibited better net clinical outcomes than warfarin for both elderly and non-elderly patients in standard-dose, but not in elderly patients in low-dose regimens. Further analysis in extremely old patients (aged $\geq 80$ years) demonstrated that standard-dose NOACs, but not low-dose NOACs, reduced IS/SE compared to warfarin [21]. Briefly, in elderly patients, standard-dose NOACs showed better efficacy and similar safety as compared to warfarin except for a trend toward more GI bleeding, whereas low-dose NOACs exhibited similar efficacy, and equivalent or better safety than warfarin. For the trend toward more GI bleeding with certain NOACs, some studies suggest avoiding concomitant antiplatelet treatment and probably considering proton pump inhibitor in elderly anticoagulated patients [36].

Some indirect comparisons among different NOACs in elderly patients were reported. A nationwide cohort study including 15361 patients aged $\geq 85$ years showed a lower risk of $\mathrm{ICH}$, mortality, and composite adverse events with dabigatran; a lower risk of ischemic stroke, $\mathrm{ICH}$, mortality, and composite adverse events with rivaroxaban; and a lower risk of mortality and composite adverse events with apixaban when compared to warfarin [27]. Alnsasra et al. reported the greatest net clinical benefit in elderly AF patients treated with warfarin with time in therapeutic range $\geq 60 \%$ or high dose NOACs (dabigatran $150 \mathrm{mg}$ twice a day, apixaban $5 \mathrm{mg}$ twice a day, rivaroxaban $20 \mathrm{mg}$ once a day). Schäfer et al. [36] calculated the net clinical benefit of 4 landmark trials of NOACs using the annualized rate of thromboembolic events prevented minus the annualized rate of major bleedings induced, along with $\mathrm{ICH}$ multiplied by different weighting factors in AF patients aged $\geq 75$ years. Compared to warfarin, the highest and most significant benefit was demonstrated in the case of apixaban, followed by edoxaban, whereas rivaroxaban or either dose of dabigatran only provided a slight numerical benefit. They reported that the higher benefit of apixaban and edoxaban was mainly driven by fewer events of major bleeding compared to warfarin. Furthermore, the increased bleeding risks with dabigatran and rivaroxaban, compared to warfarin, were mostly limited to extracranial bleeding [37].

The ELDERCARE-AF trial included elderly AF patients ( $\geq 80$ years of age) who were ineligible for OAC use at doses approved for stroke prevention and showed that edoxaban $15 \mathrm{mg}$ once daily was superior to placebo for preventing IS/SE without significant increase of major bleeding [38]. Subsequently, Chao et al. [39] performed a cohort study including 15183 elderly AF patients aged $\geq 80$ years with enrollment criteria similar to the ELDERCARE-AF trial. They showed that use of NOACs at either the full dose or reduced dose lowered ischemic strokes by $23 \%$, all-cause mortality by $61 \%$, and composite outcomes by $58 \%$, while the risks of $\mathrm{ICH}$ and major bleeding were similar as compared to the non-OAC group. In this cohort study, $40 \%$ of patients were taking dabigatran, $49 \%$ rivaroxaban, and $11 \%$ apixaban.

Notably, the optimal choice and dose of NOACs in elderly AF patients remain undetermined yet because of the absence of head-to-head comparisons in RCTs. Besides, the currently available trials differ in terms of inclusion and exclusion criteria, as well as of underlying stroke risks of study populations [37]. Therefore, it is too early to draw a robust conclusion regarding the choice of certain NOACs, and shared decision-making remains the most important step before NOACs are prescribed for elderly AF patients.

\section{IMPORTANT CLINICAL FACTORS ABOUT THE ANTICOAGULATION MANAGEMENT IN ELDERLY PATIENTS WITH AF}

Aging is usually accompanied by a gradual decline of renal function [40] and might influence the decision of OAC use. Khan et al. [41] observed that in the $36 \%$ of patients aged $\geq 75$ years with eGFR $<59 \mathrm{ml} / \mathrm{min} / 1.73 \mathrm{~m}^{2}$ at the time of NOAC initiation, all major bleeding episodes were associated with a decline in eGFR compared to baseline. Thus, 


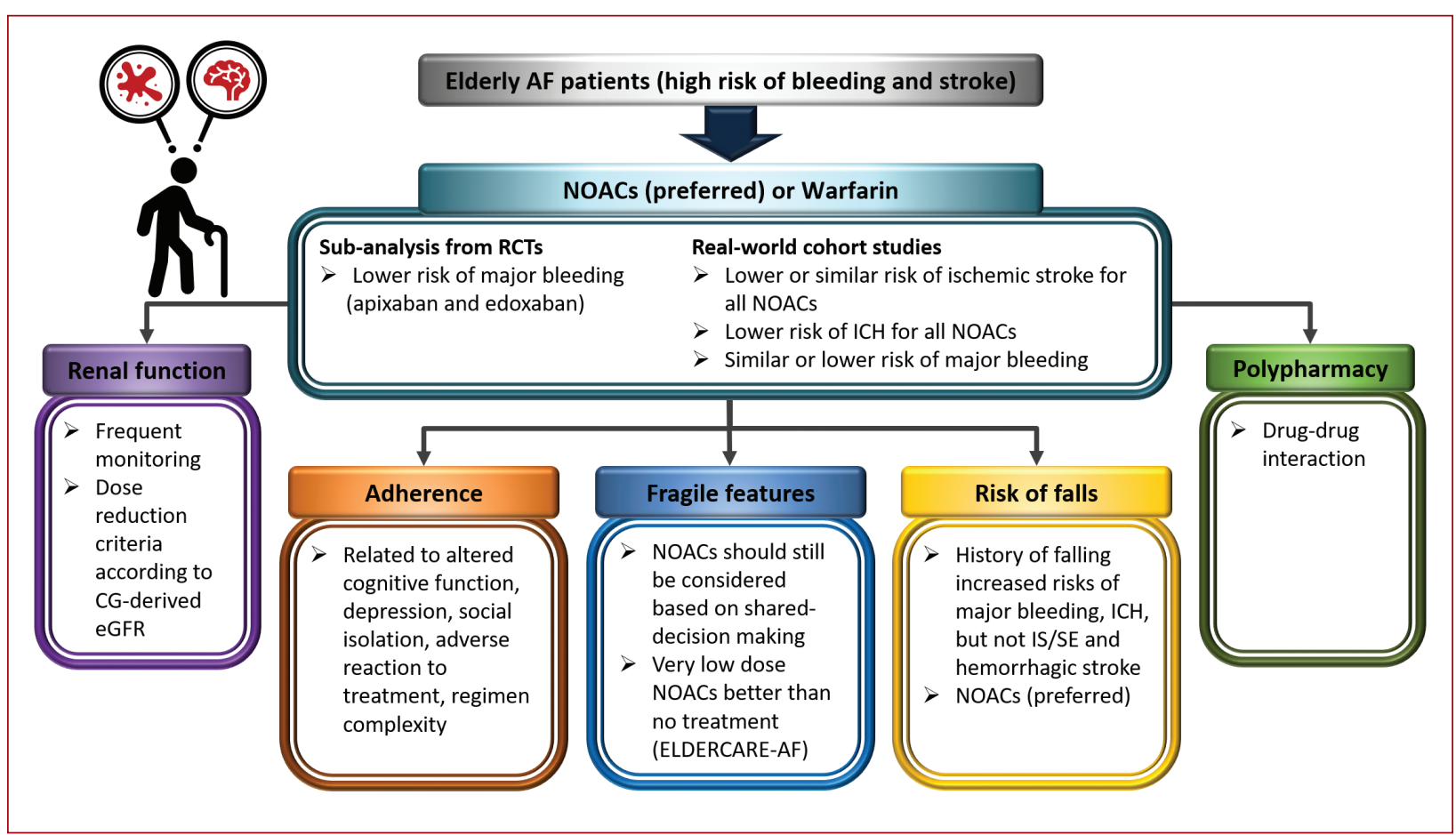

Figure 6. Considerations about the anticoagulation management in elderly patients with AF

Abbreviations: CG-derived eGFR, estimated glomerular filtration rate derived from the Cockcroft-Gault formula; IS/SE, ischemic stroke/system embolism; other - see Figures 1-3

regular monitoring of renal function is recommended in elderly anticoagulated patients to adjust the dosages of NOACs once indicated by dosage reduction criteria of each NOAC and to correct modifiable causes for patients whose renal function declines rapidly [41, 42]. A meta-analysis showed that in elderly patients, both NOACs without dose reduction in patients with creatinine clearance $(\mathrm{CrCl})$ $\geq 50 \mathrm{ml} / \mathrm{min}$ and reduced-dosed NOACs meeting appropriate dose reduction criteria in those with $\mathrm{CrCl}<50 \mathrm{ml} / \mathrm{min}$ behaved equivalently to warfarin for safety endpoints, which highlights the importance of following dose reduction criteria even for patients with impaired renal function [21]. The risk of falls with consequent bleeding is a common reason for not prescribing OACs in elderly AF patients [43]. In the subgroup analysis from the ARISTOTLE trial, about $5 \%$ of patients had a history of falling, and they had a more than the three-fold increased risk of fall and a more than the two-fold increased risk of any bone fracture during the trial period. Patients with a history of falling had higher rates of major bleeding and $\mathrm{ICH}$, but similar rates of IS/SE and hemorrhagic stroke compared to those without a history of falls. The superiority of apixaban over warfarin in relation to efficacy and safety was consistent, irrespective of the history of falls [44]. In a secondary analysis of the ENGAGE AF-TIMI 48 trial, in patients with an increased risk of falling (but not specifically a history of falls), treatment with edoxaban resulted in a greater absolute risk reduction in severe bleeding events and all-cause death as compared to warfarin [45]. Therefore, NOACs might be an attractive choice for stroke prevention in elderly patients at risk of falling.
In a meta-analysis including patients aged 63.8-85.9 years from 20 observational studies, frailty was associated with decreased OAC prescription on hospital admission, but not at discharge. It was also associated with the increased risk of stroke, all-cause mortality, symptom severity, and length of hospital stay [46]. Polypharmacy is frequent in elderly patients, and drug-drug interactions, although less common with NOACs, should be considered. Drugs affecting the P-glycoprotein transport system may potentially interact with NOACs, and dose reductions are sometimes recommended in elderly patients [47]. Adherence to therapy is an issue in elderly patients and possibly relates to altered cognitive function, depression, social isolation, adverse effects of treatment, and regimen complexity $[48,49]$. Furthermore, physiological organ changes, malnutrition, and hypoalbuminemia with heterogeneous binding to proteins may be present in a proportion of elderly patients, thus affecting the pharmacokinetics of NOACs [14]. All these risk factors should be comprehensively assessed and taken into consideration when prescribing NOACs for elderly patients (Figure 6).

\section{CONCLUSIONS}

Aging increases the risk of adverse events in elderly AF patients, but OAC use provides clinical benefits, with the oldest patients deriving the greatest advantage. Thus, the age and fear of bleeding should not be the reasons for withholding OACs. Sub-analyses and real-world cohort studies generally favor the use of NOAC over warfarin in elderly patients, but the optimal choice and dose of NOACs 
have not been determined yet. Therefore, dose adjustment according to the dose reduction criteria of each NOAC is crucial. Other risk factors potentially affecting anticoagulation treatment should be assessed carefully, such as renal function impairment, risk of falls, frailty, nutritional status, adherence to therapy, etc. More data from RCTs are urgently needed for optimal stroke prevention strategies in elderly AF patients.

\section{Article information}

\section{Conflict of interest: None declared.}

Open access: This article is available in open access under Creative Common Attribution-Non-Commercial-No Derivatives 4.0 International (CC BY-NC-ND 4.0) license, allowing to download articles and share them with others as long as they credit the authors and the publisher, but without permission to change them in any way or use them commercially. For commercial use, please contact the journal office at kardiologiapolska@ptkardio.pl.

\section{REFERENCES}

1. Lip $G Y H, K a k a r ~ P$, Watson T. Atrial fibrillation - the growing epidemic. Heart. 2007; 93(5): 542-543, doi: 10.1136/hrt.2006.110791, indexed in Pubmed: 17435064.

2. Rahman F, Kwan GF, Benjamin EJ, et al. Global epidemiology of atrial fibrillation. Nat Rev Cardiol. 2014; 11(11): 639-654, doi: 10.1038/nrcardio.2014.118, indexed in Pubmed: 25113750.

3. Chao TF, Joung B, Takahashi Y, et al. 2021 Focused update of the 2017 consensus guidelines of the Asia Pacific Heart Rhythm Society (APHRS) on stroke prevention in atrial fibrillation. J Arrhythm. 2021;37(6): 1389-1426, doi: 10.1002/joa3.12652, indexed in Pubmed: 34887945.

4. Chao TF, Joung B, Takahashi Y, et al. 2021 Focused Update Consensus Guidelines of the Asia Pacific Heart Rhythm Society on Stroke Prevention in Atrial Fibrillation: Executive Summary. Thromb Haemost. 2022; 122(1): 20-47, doi: 10.1055/s-0041-1739411, indexed in Pubmed: 34773920.

5. January CT, Wann LS, Calkins H, et al. 2019 AHA/ACC/HRS Focused Update of the 2014 AHA/ACC/HRS Guideline for the Management of Patients With Atrial Fibrillation: A Report of the American College of Cardiology/American Heart Association Task Force on Clinical Practice Guidelines and the Heart Rhythm Society in Collaboration With the Society of Thoracic Surgeons. Circulation. 2019; 140(2): e125-e151, doi: 10.1161/CIR.0000000000000665, indexed in Pubmed: 30686041.

6. Hindricks G, Potpara T, Dagres N, et al. Corrigendum to: 2020 ESC Guidelines for the diagnosis and management of atrial fibrillation developed in collaboration with the European Association for Cardio-Thoracic Surgery (EACTS): The Task Force for the diagnosis and management of atrial fibrillation of the European Society of Cardiology (ESC) Developed with the special contribution of the European Heart Rhythm Association (EHRA) of the ESC. Eur Heart J. 2021; 42(40): 4194, doi: 10.1093/eurheartj/ehab648, indexed in Pubmed: 34520521.

7. Chao TF, Wang KL, Liu CJ, et al. Age threshold for increased stroke risk among patients with atrial fibrillation: a nationwide cohort study from Taiwan. J Am Coll Cardiol. 2015; 66(12): 1339-1347, doi: 10.1016/j. jacc.2015.07.026, indexed in Pubmed: 26383720.

8. Pisters R, Lane DA, Nieuwlaat $R$, et al. A novel user-friendly score (HASBLED) to assess 1-year risk of major bleeding in patients with atrial fibrillation: the Euro Heart Survey. Chest. 2010; 138(5): 1093-1100, doi: 10.1378/chest.10-0134, indexed in Pubmed: 20299623.

9. Esteve-Pastor MA, Rivera-Caravaca JM, Roldan V, et al. Long-term bleeding risk prediction in 'real world' patients with atrial fibrillation: Comparison of the HAS-BLED and ABC-Bleeding risk scores. The Murcia Atrial Fibrillation Project. Thromb Haemost. 2017; 117(10): 1848-1858, doi: 10.1160/TH1707-0478, indexed in Pubmed: 28799620.

10. Chao TF, Chiang CE, Liao JN, et al. Comparing the Effectiveness and Safety of Nonvitamin K Antagonist Oral Anticoagulants and Warfarin in Elderly Asian Patients With Atrial Fibrillation: A Nationwide Cohort Study. Chest.
2020; 157(5): 1266-1277, doi: 10.1016/j.chest.2019.11.025, indexed in Pubmed: 31809694

11. Patti G, Lucerna M, Pecen L, et al. Thromboembolic Risk, Bleeding Outcomes and Effect of Different Antithrombotic Strategies in Very Elderly Patients With Atrial Fibrillation: A Sub-Analysis From the PREFER in AF (PREvention oF Thromboembolic Events - European Registry in Atrial Fibrillation). J Am Heart Assoc. 2017; 6(7), doi: 10.1161/jaha.117.005657, indexed in Pubmed: 28736385.

12. Kodani $\mathrm{E}$, Atarashi $\mathrm{H}$, Inoue $\mathrm{H}$, et al. J-RHYTHM Registry Investigators, J-RHYTHM Registry Investigators. Use of warfarin in elderly patients with non-valvular atrial fibrillation - subanalysis of the J-RHYTHM Registry. Circ J. 2015; 79(11): 2345-2352, doi: 10.1253/circj.CJ-15-0621, indexed in Pubmed: 26329097.

13. Krittayaphong $R$, Boonyapiphat $T$, Wongvipaporn $C$, et al. Age-Related Clinical Outcomes of Patients with Non-Valvular Atrial Fibrillation: Insights from the COOL-AF Registry. Clin Interv Aging. 2021; 16: 707-719, doi: 10.2147/CIA.S302389, indexed in Pubmed: 33953549.

14. Russo V, Carbone A, Rago A, et al. Direct oral anticoagulants in octogenarians with atrial fibrillation: it is never too late. J Cardiovasc Pharmacol. 2019; 73(4): 207-214, doi: 10.1097/FJC.0000000000000661, indexed in Pubmed: 30855404

15. Chao TF, Liu CJ, Lin YJ, et al. Validation of a Modified CHA2DS2-VASC Score for Stroke Risk Stratification in Asian Patients With Atrial Fibrillation: A Nationwide Cohort Study. Stroke. 2016; 47(10): 2462-2469, doi: 10.1161/STROKEAHA.116.013880, indexed in Pubmed: 27625386.

16. Chao TF, Chiang CE, Chan YH, et al. Oral anticoagulants in extremely-high-risk, very elderly ( $>90$ years) patients with atrial fibrillation. Heart Rhythm. 2021; 18(6):871-877, doi: 10.1016/j.hrthm.2021.02.018, indexed in Pubmed: 33640447

17. Connolly SJ, Ezekowitz MD, Yusuf S, et al. Dabigatran versus warfarin in patients with atrial fibrillation. N Engl J Med. 2009; 361(12): 1139-1151, doi: 10.1056/NEJMoa0905561, indexed in Pubmed: 19717844.

18. Patel MR, Mahaffey KW, Garg J, et al. Rivaroxaban versus warfarin in nonvalvular atrial fibrillation. N Engl J Med. 2011; 365(10): 883-891, doi: 10.1056/NEJMoa1009638, indexed in Pubmed: 21830957.

19. Granger $\mathrm{CB}$, Alexander JH, McMurray JJV, et al. A pixaban versus warfarin in patients with atrial fibrillation. N Engl J Med. 2011; 365(11): 981-992, doi: 10.1056/NEJMoa1107039, indexed in Pubmed: 21870978.

20. Giugliano RP, Ruff CT, Braunwald $E$, et al. Edoxaban versus warfarin in patients with atrial fibrillation. N Engl J Med. 2013; 369(22): 2093-2104, doi: 10.1056/NEJMoa1310907, indexed in Pubmed: 24251359.

21. Kim IS, Kim HJ, Kim TH, et al. Non-vitamin K antagonist oral anticoagulants have better efficacy and equivalent safety compared to warfarin in elderly patients with atrial fibrillation: A systematic review and meta-analysis. J Cardiol. 2018; 72(2): 105-112, doi: 10.1016/j.jjcc.2018.01.015, indexed in Pubmed: 29519547.

22. Eikelboom JW, Wallentin L, Connolly SJ, et al. Risk of bleeding with 2 doses of dabigatran compared with warfarin in older and younger patients with atrial fibrillation: an analysis of the randomized evaluation of long-term anticoagulant therapy (RE-LY) trial. Circulation. 2011;123(21): 2363-2372, doi: 10.1161/CIRCULATIONAHA.110.004747, indexed in Pubmed: 21576658

23. Kato ET, Giugliano RP, Ruff CT, et al. Efficacy and Safety of Edoxaban in Elderly Patients With Atrial Fibrillation in the ENGAGE AF-TIMI 48 Trial. J Am Heart Assoc. 2016; 5(5), doi: 10.1161/JAHA.116.003432, indexed in Pubmed: 27207971

24. Halvorsen $\mathrm{S}$, Atar D, Yang H, et al. Efficacy and safety of apixaban compared with warfarin according to age for stroke prevention in atrial fibrillation: observations from the ARISTOTLE trial. Eur Heart J. 2014; 35(28): 18641872, doi: 10.1093/eurheartj/ehu046, indexed in Pubmed: 24561548.

25. Goodman SG, Wojdyla DM, Piccini JP, et al. Factors associated with major bleeding events: insights from the ROCKET AF trial (rivaroxaban once-daily oral direct factor $\mathrm{Xa}$ inhibition compared with vitamin $\mathrm{K}$ antagonism for prevention of stroke and embolism trial in atrial fibrillation). J Am Coll Cardiol. 2014; 63(9): 891-900, doi: 10.1016/j.jacc.2013.11.013, indexed in Pubmed: 24315894.

26. Lai CL, Chen HM, Liao MT, et al. Dabigatran, rivaroxaban, and warfarin in the oldest adults with atrial fibrillation in Taiwan. J Am Geriatr Soc. 2018; 66(8): 1567-1574, doi: 10.1111/jgs.15430, indexed in Pubmed: 29975405. 
27. Tsai CT, Liao JN, Chen SJ, et al. Non-vitamin K antagonist oral anticoagulants versus warfarin in AF patients $\geq 85$ years. Eur J Clin Invest. 2021; 51(6): e13488, doi: 10.1111/eci.13488, indexed in Pubmed: 33420738.

28. Chan YH, Lee HF, See LC, et al. Effectiveness and safety of four direct oral anticoagulants in Asian patients with nonvalvular atrial fibrillation. Chest. 2019; 156(3): 529-543, doi: 10.1016/j.chest.2019.04.108, indexed in Pubmed: 31103697.

29. Hanon O, Vidal JS, Pisica-Donose G, et al. Bleeding risk with rivaroxaban compared with vitamin $\mathrm{K}$ antagonists in patients aged 80 years or older with atrial fibrillation. Heart. 2021; 107(17): 1376-1382, doi: 10.1136/heartjnl-2020-317923, indexed in Pubmed: 33262185.

30. Deitelzweig S, Keshishian A, Li X, et al. Comparisons between oral anticoagulants among older nonvalvular atrial fibrillation patients. J Am Geriatr Soc. 2019; 67(8): 1662-1671, doi: 10.1111/jgs.15956, indexed in Pubmed: 31112292.

31. Russo V, Attena E, Di Maio M, et al. Clinical profile of direct oral anticoagulants versus vitamin $\mathrm{K}$ anticoagulants in octogenarians with atrial fibrillation: a multicentre propensity score matched real-world cohort study. J Thromb Thrombolysis. 2020; 49(1): 42-53, doi: 10.1007/s11239019-01923-9, indexed in Pubmed: 31385163.

32. Hanon $O$, Jeandel $C$, Jouanny $P$, et al. Anticoagulant treatment in elderly patients with atrial fibrillation: position paper. Geriatr Psychol Neuropsychiatr Vieil. 2019; 17(4):341-355, doi: 10.1684/pnv.2019.0834, indexed in Pubmed: 31848123.

33. Cheng $\mathrm{WH}$, Chiang CE, Lin YJ, et al. Non-Vitamin K Antagonist Oral Anticoagulants in Elderly ( $\geq 85$ years) Patients With Newly Diagnosed Atrial Fibrillation: Changing Clinical Practice and Outcomes for Stroke Prevention in a Nationwide Cohort Study. Mayo Clin Proc. 2021; 96(1): 52-65, doi: 10.1016/j.mayocp.2020.08.042, indexed in Pubmed: 33413835.

34. Chan $\mathrm{YH}$, Chao TF, Lee HF, et al. Impacts of different renal function estimation formulas on dosing of DOACs and clinical outcomes. J Am Coll Cardiol. 2020; 76(15): 1808-1810, doi: 10.1016/j.jacc.2020.08.025, indexed in Pubmed: 33032742.

35. Chan YH, Chao TF, Lee HF, et al. Different renal function equations and dosing of direct oral anticoagulants in atrial fibrillation. JACC: Asia. 2022, doi: 10.1016/j.jacasi.2021.11.006.

36. Schäfer A, Flierl U, Berliner D, et al. Anticoagulants for stroke prevention in atrial fibrillation in elderly patients. Cardiovasc Drugs Ther. 2020; 34(4): 555-568, doi: 10.1007/s10557-020-06981-3, indexed in Pubmed: 32350792.

37. Patti G, Cavallari I, Hanon O, et al. The safety and efficacy of non-vitamin $\mathrm{K}$ antagonist oral anticoagulants in atrial fibrillation in the elderly. Int J Cardiol. 2018; 265: 118-124, doi: 10.1016/j.ijcard.2018.02.066, indexed in Pubmed: 29885678.

38. Okumura K, Akao M, Yoshida T, et al. Low-Dose Edoxaban in Very Elderly Patients with Atrial Fibrillation. N Engl J Med. 2020; 383(18): 1735-1745, doi: 10.1056/NEJMoa2012883, indexed in Pubmed: 32865374.
39. Chao TF, Chan YH, Chiang CE, et al. Stroke prevention with direct oral anticoagulants in high risk elderly atrial fibrillation patients at increased bleeding risk. Eur Heart J Qual Care Clin Outcomes. 2021 [Epub ahead of print], doi: 10.1093/ehjqcco/qcab076, indexed in Pubmed: 34694379.

40. Hiasa KI, Kaku H, Inoue $\mathrm{H}$, et al. Age-Related Differences in the Clinical Characteristics and Treatment of Elderly Patients With Atrial Fibrillation in Japan - Insight From the ANAFIE (All Nippon AF In Elderly) Registry. Circ J. 2020; 84(3): 388-396, doi: 10.1253/circj.CJ-19-0898, indexed in Pubmed: 31969518.

41. Khan F, Huang H, Datta YH. Direct oral anticoagulant use and the incidence of bleeding in the very elderly with atrial fibrillation. J Thromb Thrombolysis. 2016; 42(4): 573-578, doi: 10.1007/s11239-016-1410-z, indexed in Pubmed: 27520093.

42. Andreotti F, Rocca B, Husted S, et al. Antithrombotic therapy in the elderly: expert position paper of the European Society of Cardiology Working Group on Thrombosis. Eur Heart J. 2015; 36(46): 3238-3249, doi: 10.1093/eurheartj/ehv304, indexed in Pubmed: 26163482.

43. Hylek EM, D'Antonio J, Evans-Molina C, et al. Translating the results of randomized trials into clinical practice: the challenge of warfarin candidacy among hospitalized elderly patients with atrial fibrillation. Stroke. 2006; 37(4): 1075-1080, doi: 10.1161/01.STR.0000209239.71702.ce, indexed in Pubmed: 16527999.

44. Rao MP, Vinereanu D, Wojdyla DM, et al. Clinical outcomes and history of fall in patients with atrial fibrillation treated with oral anticoagulation: insights from the ARISTOTLE trial. Am J Med. 2018; 131(3): 269-275.e2, doi: 10.1016/j.amjmed.2017.10.036, indexed in Pubmed: 29122636.

45. Steffel J, Giugliano RP, Braunwald E, et al. Edoxaban versus warfarin in atrial fibrillation patients at risk of falling: ENGAGE AF-TIMI 48 analysis. J Am Coll Cardiol. 2016; 68(11): 1169-1178, doi: 10.1016/j.jacc.2016.06.034, indexed in Pubmed: 27609678.

46. Wilkinson C, Todd O, Clegg A, et al. Management of atrial fibrillation for older people with frailty: a systematic review and meta-analysis. Age Ageing. 2019; 48(2): 196-203, doi: 10.1093/ageing/afy180, indexed in Pubmed: 30445608.

47. LaFromboise TD. American Indian mental health policy. Am Psychol. 1988; 43(5): 388-397, doi: 10.1037//0003-066x.43.5.388, indexed in Pubmed: 3389584.

48. Gellad WF, Grenard JL, Marcum ZA. A systematic review of barriers to medication adherence in the elderly: looking beyond cost and regimen complexity. Am J Geriatr Pharmacother. 2011; 9(1): 11-23, doi: 10.1016/j. amjopharm.2011.02.004, indexed in Pubmed: 21459305.

49. Wimmer BC, Cross AJ, Jokanovic N, et al. Clinical outcomes associated with medication regimen complexity in older people: a systematic review. J Am Geriatr Soc. 2017; 65(4): 747-753, doi: 10.1111/jgs.14682, indexed in Pubmed: 27991653. 